\title{
Limethason reduces airway inflammation in a murine model of ovalbumin-induced chronic asthma without causing side effects
}

\author{
SIYU LI $^{1 *}$, ZHIPING MIAO $^{1 *}$, YE TIAN $^{1}$, HAOYU WANG $^{1}$, SHUAI WANG $^{1}$, \\ TIANYUAN HE ${ }^{1}$, YUE YANG ${ }^{1}$, PENG WANG ${ }^{1}$, MENGYAO MA ${ }^{1}$, TUANMIN YANG ${ }^{2}$, \\ TAO CHEN $^{3}$, ZHIYONG LIU ${ }^{4}, \mathrm{JUNHONG} \mathrm{GAO}^{4}, \mathrm{CHU} \mathrm{CHEN}^{2}$ and AIRONG QIAN ${ }^{1}$
}

${ }^{1}$ Key Laboratory for Space Bioscience and Biotechnology, Institute of Special Environmental Biophysics,
School of Life Sciences, Northwestern Polytechnical University, Xi'an, Shaanxi 710072; ${ }^{2}$ Clinical Laboratory of
Honghui Hospital, Xi'an Jiaotong University College of Medicine, Xi'an, Shanxi 710054; ${ }^{3}$ Xi'an Libang
Pharmaceutical Co., Ltd., Xi'an, Shaanxi 710075; ${ }^{4}$ CNGC Institute of Industrial Health, Xi'an, Shanxi 710065, P.R. China

Received June 1, 2017; Accepted October 5, 2017

DOI: 10.3892/etm.2018.5691

\begin{abstract}
Airway inflammation is the major pathological feature of asthma. Thus, the current therapeutic strategy for asthma is to control inflammation. Limethason, an anti-inflammation drug, is widely used in rheumatoid arthritis treatment. The aim of the present study was to detect the anti-inflammatory effect and side effects of limethason on airways that were sensitized with ovalbumin in a murine model of chronic asthma. In the present study, BALB/c mice were sensitized with ovalbumin. Airway hyperresponsiveness was estimated, and hematoxylin and eosin staining, Periodic acid-Schiff staining and bronchoalveolar lavage were used to detect the effect on chronic asthma. Limethason effectively reduced airway hyperresponsiveness, and inhibited inflammatory cell infiltration and mucus secretion. Bronchoalveolar lavage fluid analysis revealed that limethason suppressed levels of airway eosinophils. In the period of treatment, limethason exhibited no influence on morphology of the femoral head, bone mineral content or bone mineral density, which were detected by histological studies and dual-energy X-ray absorptiometry. The index of liver, spleen, kidney, gastrocnemius and
\end{abstract}

Correspondence to: Professor Airong Qian, Key Laboratory for Space Bioscience and Biotechnology, Institute of Special Environmental Biophysics, School of Life Sciences, Northwestern Polytechnical University, 127 Youyi West Road, Xi'an, Shaanxi 710072, P.R. China

E-mail: qianair@nwpu.edu.cn

Dr Chu Chen, Clinical Laboratory of Honghui Hospital, Xi'an Jiaotong University College of Medicine, 555 Youyi East Road, Xi'an, Shaanxi 710054, P.R. China

E-mail: chuchen09cqmu@163.com

*Contributed equally

Key words: asthma, limethason, inflammation, airway hyperresponsiveness, treatment brown adipose tissue also demonstrated that limethason had no adverse effects on organs and tissues. The present study revealed that limethason could effectively reduce inflammation in an asthma mouse model without side effects. Therefore, limethason may have therapeutic potential for treating chronic asthma clinically.

\section{Introduction}

As a common inflammatory disease, asthma is characterized by reduced respiratory function and increased infiltration of leukocytes, particularly eosinophils. This inflammation usually leads to airway bronchoconstriction, increased airway hyperresponsiveness (AHR) and mucus production (1). Controlling airway inflammation is currently the primary strategy of asthma management (2). Synthetic glucocorticoids (GCs) are widely used to treat chronic and acute inflammatory conditions worldwide $(3,4)$. Dexamethasone, as a typical $\mathrm{GC}$, is the standard treatment for multiple diseases, including asthma (5), arthritis (6) and autoimmune disorders (7). However, the clinical use of dexamethasone is limited by its side effects at high doses in short-term treatment, or at low doses in long-term treatment (8). Dexamethasone administration is one of the most common causes of osteoporosis (9) and osteonecrosis of femoral head (10). Therefore, a clinical replacement for dexamethasone is urgently required in order to treat chronic asthma without generating any adverse reactions.

Limethason is a derivative of dexamethasone (10). It has previously been demonstrated that limethason can effectively ameliorate arthritis, macrophage-rich graft vs. host disease, arteriosclerosis and macular edema (11-13). In certain chronic inflammatory diseases, including Rheumatoid arthritis and hemophagocytic syndrome, limethason is 2-5 times more potent than dexamethasone phosphate against inflammation (14). As an ester prodrug of dexamethasone, limethason has a markedly increased lipophilicity (15).

Although the efficacy of limethason has been verified in multiple disorders, to the best of our knowledge, its function in asthma has not yet been reported. In the present study, the effects and adverse reactions of limethason were investigated 
in an ovalbumin (OVA)-induced chronic asthma mouse model. The present research could provide the basis for a new strategy of chronic asthma therapy in the clinic.

\section{Materials and methods}

Animals. A total of 48 male BALB/c mice (weight, 20.27 \pm 1.09 ; aged 6-8 weeks) were purchased from the Fourth Military Medical University (Xi'an, China). Prior to the experiments, the mice were kept under standard laboratory conditions (temperature, $23-25^{\circ} \mathrm{C}$; humidity, $40-60 \%$; with access to a 12-h light/dark cycle) for 1 week. All mice were provided with water and standard chow ad libitum. All animal protocols conformed to the guidelines of the National Animal Welfare Law of China, and experiments were performed in accordance with the Guidelines for the Care and Use of Laboratory Animals (16). The study protocols were approved by the Ethics Committee of Northwestern Polyechnical University (Xi'an, China).

The model of chronic asthma establishing. Mice were randomly divided into four groups ( $\mathrm{n}=12$ in each group): A normal control (NC) group, an OVA group, a dexamethasone and OVA (DEX + OVA) group and a limethason and OVA (LIM + OVA) group. Except for the NC group, all mice were sensitized with intraperitoneal injection of $10 \mu \mathrm{g}$ OVA (Sigma-Aldrich; Merck KGaA, Darmstadt, Germany) and $100 \mu \mathrm{g}$ aluminium hydroxide (Sigma-Aldrich; Merck KGaA) in $0.2 \mathrm{ml}$ saline at days 0 and 14 . Mice in the $\mathrm{NC}$ group were treated with $0.2 \mathrm{ml}$ saline in the same way. From day 15, the mice were challenged with $2.5 \%$ (w/v) OVA (Sangon Biotech Co., Ltd., Shanghai, China) for 30 min using a medical gas atomizer(KYWH-1006; Shenzhen Lijian Medical Technology Co., Ltd., Shenzhen, China) after intraperitoneal injecting $1 \mathrm{mg} / \mathrm{kg}$ dexamethasone sodium phosphate (China National Medicines Co., Ltd., Shanghai, China) in the DEX + OVA group or $1.6 \mathrm{mg} / \mathrm{kg}$ limethason (MitsubishiPharma Co., Ltd., Guangzhou, China) in the LIM + OVA group. This was performed three times per week for a total of 9 weeks. The NC group was injected with $0.2 \mathrm{ml}$ saline instead of dexamethasone or limethason. Mice were sacrificed 8 days after the last challenge (day 87) to characterize the effects of limethason on the airways of chronic asthma animals. Hematoxylin and eosin (H\&E) staining and Periodic acid-Schiff (PAS) staining were performed using 6 mice per each group. The remaining 6 mice in each group were used for bronchoalveolar lavage.

Measurement of AHR. AHR was estimated in unrestrained and conscious mice by whole-body plethysmography (Buxco; Data Sciences International, New Brighton, MN, USA) after the last aerosol challenge. Each mouse was placed in a chamber, then exposed to aerosolized PBS, followed by increasing concentrations of methacholine solutions (Sigma-Aldrich; Merck KGaA): 6.25, 12.5, 25 and $50 \mathrm{mg} / \mathrm{ml}$ dissolved in PBS. After adapting for 5 min, each exposure lasted for $3 \mathrm{~min}$. An index of airway obstruction was measured during the response stage, which lasted $5 \mathrm{~min}$. Finally, each mouse recovered for $3 \mathrm{~min}$. Response and recovery stage was repeated after each concentration of methacholine. In the process of measuring AHR, some mice did not respond well to the experiment and became eclamptic or showed signs of difficulty in breathing, however mice did not succumb to the conditions. Subsequently, data were not collected for some mice in the NC $(n=6)$, OVA $(n=6)$, DEX + OVA $(n=6)$ and LIM + OVA $(n=6)$ groups. However, at least five mice were provided in each group.

Leukocyte count in bronchoalveolar lavage fluid (BALF). BALF analysis was performed in 6 mice in each group after sacrifice. The esophagus of mice were cut with operating scissors, $\sim 2 \mathrm{~mm}$ incision was made, and cold PBS $\left(4^{\circ} \mathrm{C}\right)$ was slowly instilled into the lungs $0.5 \mathrm{ml}$ at a time, for a total of three times $(1.5 \mathrm{ml})$. In the process of BAL, the operator failed to recover the fluid which was instilled into the lungs of some mice. However, the fluids from at least 5 mice per group were successfully collected. Data were not collected from 1 mouse in the NC, OVA and DEX + OVA group. The fluid was immediately centrifuged at $4^{\circ} \mathrm{C}, 100 \mathrm{x}$ g for $10 \mathrm{~min}$. The total number of cells was counted on $\geq 6$ squares of a hemocytometer. Then, cell pellets were suspended in $1 \mathrm{ml}$ of PBS, and $100 \mu \mathrm{l}$ of each solution was placed onto a slide. After the slides were dried, cells were fixed in paraformaldehyde for $20 \mathrm{~min}$ at $25^{\circ} \mathrm{C}$ and stained using Diff-Quik stain reagents (Wuhan Goodbio Biotechnology Co., Ltd., China), according to the manufacturer's protocol. Cells were counted manually using a light microscope and a hemocytometer.

Histopathology of lung and bone tissue, the index of organs/tissues were measured. Hematoxylin and eosin (H\&E) staining and periodic acid-Schiff (PAS) staining were conducted after mice were sacrificed. Lung tissues were fixed in $4 \%(\mathrm{v} / \mathrm{v})$ paraformaldehyde for $24 \mathrm{~h}$ at $4{ }^{\circ} \mathrm{C}$ before embedding in paraffin. Mouse femurs were obtained after sacrifice and decalcified in 10\% EDTA for 1 month after being fixed in paraformaldehyde fixed for $24 \mathrm{~h}$ at $4^{\circ} \mathrm{C}$. Sections of fixed paraffin lung tissues were cut to a thickness of $5 \mu \mathrm{m}$ using the microtome, then stained with $\mathrm{H} \& \mathrm{E}$ at room temperature for $28 \mathrm{~min}$ (Beyotime Institute of Biotechnology, Shanghai, China). Lung tissues were also subjected to PAS reagent at room temperature for $22 \mathrm{~min}$ (Wuhan Goodbio Biotechnology Co., Ltd.). The sections were visualized with a light microscope.

While lung tissues were obtained, liver, spleen, kidney, gastrocnemius and brown adipose tissue were also extracted. The weight of these organs and tissues was measured using an electronic scale and calculated as follows: Organ index=organ weight/body weight; Tissue index=tissue weight/body weight. In the process of obtaining the organs and tissues, some of which were incomplete due to human error. However, at least five mice were provided in each group.

Analysis of bone mineral content (BMC) and bone mineral density (BMD) using dual-energy X-ray absorptiometry (DXA). A DXA device (InAlyzer, MEDIKORS, Inc., Seongnam, Korea) was used to measure the BMC and BMD of experimental mice on day 78. The detection sensitivity of the DXA instrument was $0.001 \mathrm{~g} / \mathrm{cm}^{2}$. A standard calibration block was used to calibrate the DXA device before measurements were made, according to the operator's manual. BMC 
A

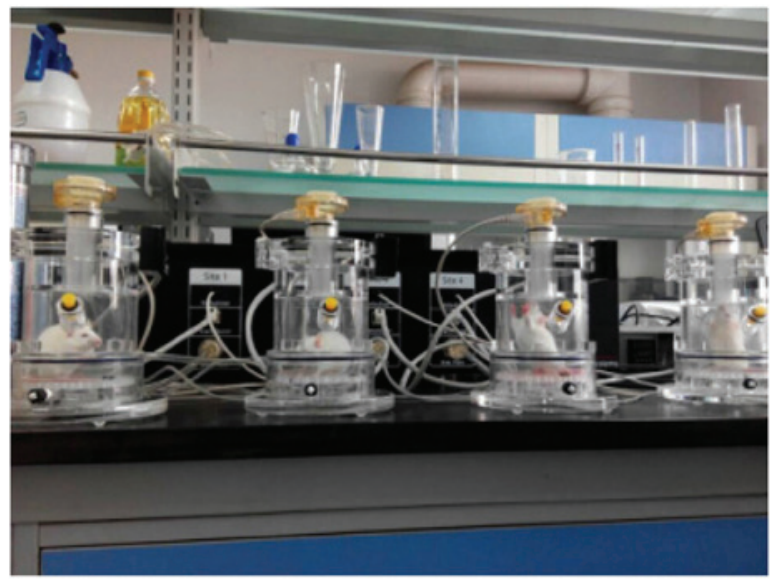

B

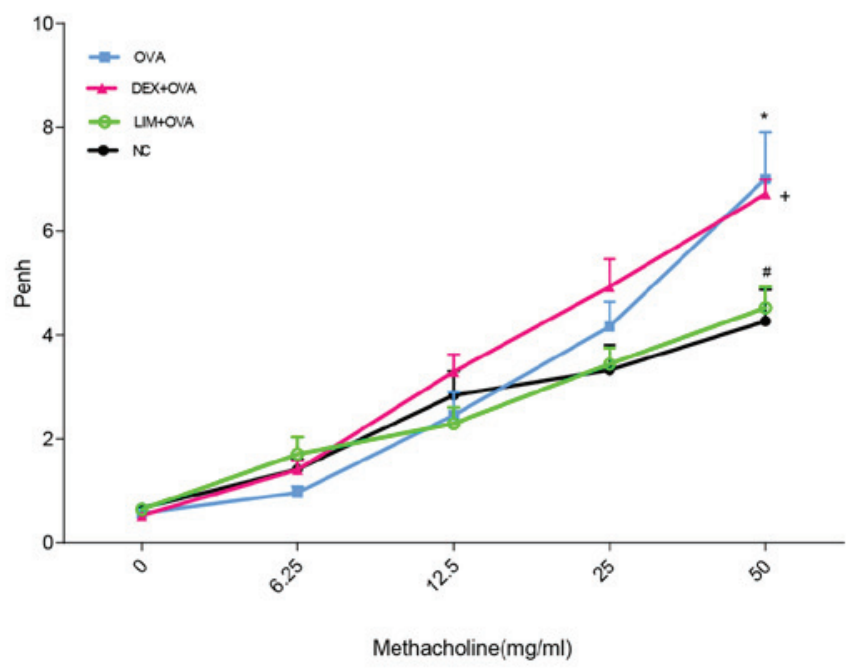

Figure 1. Effect of limethason treatment on AHR. (A) AHR measurement equipment. (B) AHR was measured at day 8 after the last OVA challenge, and all mice were administered with methacholine $(6.25-50 \mathrm{mg} / \mathrm{ml})$. NC group, $\mathrm{n}=6$; OVA group, $\mathrm{n}=6$; DEX + OVA group, $\mathrm{n}=6$; LIM + OVA group, $\mathrm{n}=6$. Data are expressed as the mean \pm standard error of the mean. ${ }^{*} \mathrm{P}<0.05$ vs. $\mathrm{NC} ;{ }^{\#} \mathrm{P}<0.05$ vs. OVA; ${ }^{+} \mathrm{P}<0.05$ vs. LIM + OVA. AHR, airway hyperresponsiveness; $\mathrm{NC}$, normal control; OVA, ovalbumin; LIM, limethason; DEX, dexamethasone; penh, enhanced pause.

and BMD measurements were taken after mice from the four groups had been anesthetized with $1.5 \%$ sodium pentobarbital (50 $\mathrm{mg} / \mathrm{kg}$, intraperitoneal injection; Kehao Biotech Co., Ltd., Xi'an, China.). The BMC and BMD of the femora and total body were obtained. The mean BMD at each site was recorded. In the process of measuring BMC and BMD, The data were not included for some mice in the NC group $(n=4)$ and LIM + OVA group ( $\mathrm{n}=1)$ as unconscious movement during imaging resulted in inaccurate data. Subsequently data was not collected in all mice. However, data was collected in at least seven mice per group.

Statistical analysis. Statistical differences among groups were analyzed by one-way analysis of variance, followed by Tukey's multiple comparison test. Statistical analysis was performed using GraphPad Prism 5.0 (GraphPad Software, Inc., La Jolla, CA, USA). Data are presented as the mean \pm standard error of the mean. $\mathrm{P}<0.05$ was considered to indicate a statistically significant difference.

\section{Results}

Limethason decreases AHR. To evaluate the effects of limethason on airway function in a murine chronic asthma model, AHR to methacholine was examined at day 8 after the final OVA challenge using whole-body plethysmography (Fig. 1A). With increased doses of methacholine, enhanced pause (penh) values increased to different degrees in the NC, OVA, DEX + OVA and LIM + OVA groups (Fig. 1B). At a concentration of $50 \mathrm{mg} / \mathrm{ml}$, the OVA group increased 1.7-fold $(\mathrm{P}<0.05)$ compared with the NC group. The penh value of DEX + OVA was slightly lower compared with the OVA group, but the difference was not observed to be significant. In the LIM + OVA group, the penh values were similar to the NC group, and decreased by $34.3 \pm 5.14 \%$ compared with the DEX + OVA group $(\mathrm{P}<0.05)$.
Limethason reduces inflammation in lung tissue. To detect the anti-inflammatory effects of limethason, lung tissues were collected after the last OVA challenge. In the OVA group, leukocytes infiltrated into and around the bronchiole and mucous membrane, epithelial cells detached from the bronchiole, and the number of goblet cells increased compared with the NC group. (Fig. 2). Meanwhile, the airway smooth muscle became thicker. In the DEX + OVA group, epithelial cells detached from the bronchiole, but leukocytes had infiltrated less compared with the OVA group and there was no obvious thickening of smooth muscle. In the LIM + OVA group, infiltration of leukocytes was reduced compared with the OVA group, and epithelial cells did not detach from the bronchiole. However, there was no obvious thickening of smooth muscle.

Limethason reduces OVA-induced eosinophilia in BALF. To evaluate the suppression of eosinophilia by limethason, after the last OVA challenge, cells were classified and counted as a percentage of total leukocytes in the BALF (Fig. 3). In the OVA group, a 5.8-fold increase in the level of eosinophils was observed compared with the NC group $(\mathrm{P}<0.001)$. Following limethason treatment, the percentage of eosinophils decreased by $47.2 \pm 7.1 \%$ compared with the OVA group $(\mathrm{P}<0.01)$. Following dexamethasone treatment the percentage of eosinophils decreased by $39.3 \pm 13.23 \%$ compared with the OVA group. The level of macrophages in the OVA group was observed to be $45.2 \pm 5.9 \%$ lower compared with the NC group $(\mathrm{P}<0.01)$. Following limethason treatment, the level of macrophages increased by $50.7 \pm 15.1 \%$ compared with the OVA group. The level of macrophages in the DEX + OVA group decreased by $32.6 \pm 8.7 \%$ compared with the NC group $(\mathrm{P}<0.05)$.

Limethason suppresses mucus overproduction. One of the key characteristics of airway remodeling is mucus hypersecretion. 

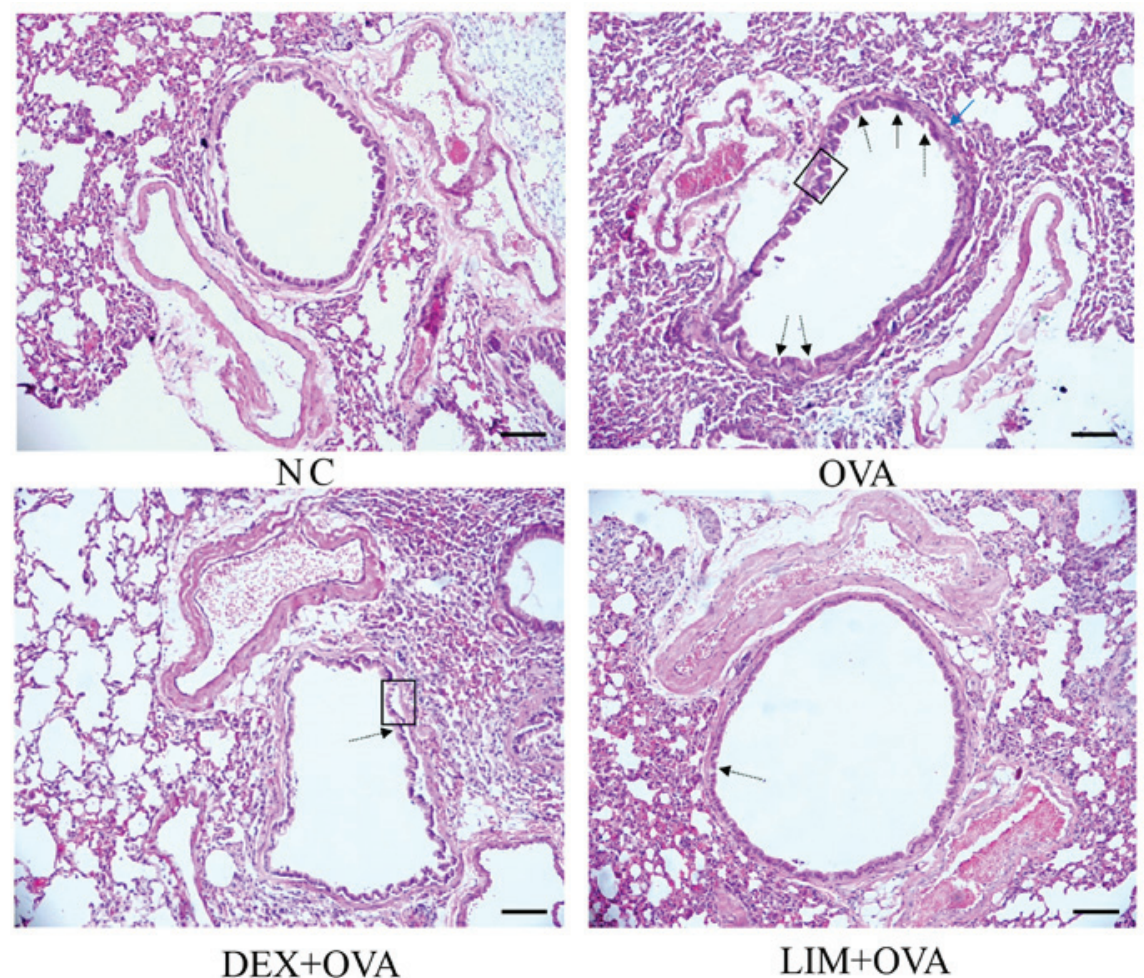

Figure 2. Effect of limethason on airway structure. Hematoxylin and eosin staining of lung sections. Scale bar=100 $\mu \mathrm{m}$. Arrows indicate changes in the airway. Black arrows indicate leukocytes; dashed arrows represent goblet cells; boxes represents that epithelial cells detached from the bronchiole; and the blue arrow indicates smooth muscle. NC, normal control; OVA, ovalbumin; LIM, limethason; DEX, dexamethasone.

PAS staining was performed to assess the quantity of mucus in lung tissue. In the OVA group, abundant mucus was observed, indicated by increased violet color in the bronchial airways, in comparison with the NC group. However, mucus content was markedly decreased in the DEX + OVA and LIM + OVA groups, with the largest decrease in the LIM + OVA group. These results suggested that limethason reduces mucus hypersecretion that occurs in the process of airway remodeling (Fig. 4).

Limethason exerts little influence on the morphology of femoral head, BMC or BMD. H\&E staining of the femur was performed in order to evaluate the impact of limethason on bone tissue. BMC and BMD were tested by DXA 1 week before mice were sacrificed. In the NC group, trabecular bone was arranged neatly and completely with normal thickness. The bone lacuna of the femoral head was predominantly filled, while staining of cell nuclei was homogeneous. There were no notable differences in the OVA, DEX + OVA or LIM + OVA groups compared with the NC group (Fig. 5A). The BMC in the OVA, DEX + OVA and LIM + OVA groups was similar to the NC group (Fig. 5B). For total BMD, the LIM + OVA and DEX + OVA group were not significantly different from the $\mathrm{NC}$ group (Fig. 5C). However, BMD in the OVA group was significantly lower compared with the $\mathrm{NC}$ group $(\mathrm{P}<0.01)$. These results suggested that limethason has a low risk of causing osteonecrosis and bone loss.

Limethason has no adverse impact on liver, spleen, kidney, gastrocnemius or brown adipose tissue. To assess whether limethason has side effects on organs and tissues

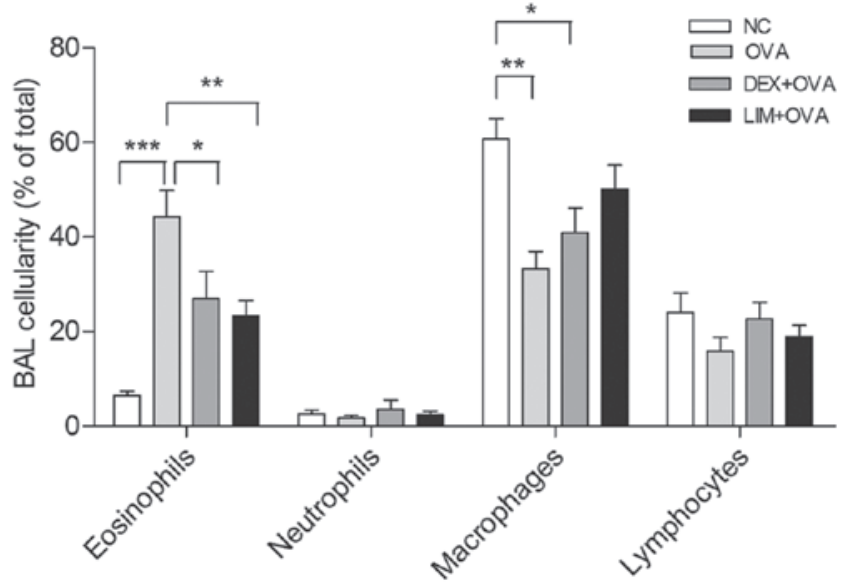

Figure 3. Effect of limethason on inflammatory cell response. Lymphocytes, macrophages, neutrophils and eosinophils were counted in BAL fluid analysis. NC group, $\mathrm{n}=5$; OVA group, $\mathrm{n}=5$; $\mathrm{DEX}+$ OVA group, $\mathrm{n}=5$, LIM + OVA group, $n=6$. Data are presented as the mean \pm standard error of the mean. ${ }^{*} \mathrm{P}<0.05,{ }^{* *} \mathrm{P}<0.01,{ }^{* * * *} \mathrm{P}<0.001$. BAL, bronchoalveolar lavage; NC, normal control; OVA, ovalbumin; LIM, limethason; DEX, dexamethasone.

in the process of treatment, all organs and tissues were collectesd after the last OVA challenge. The weight of liver, spleen, kidney, gastrocnemius and brown adipose tissue of mice were measured. No significant differences in the organ index of kidney, spleen or liver were identified between the NC, OVA, DEX + OVA or LIM + OVA groups (Fig. 6A-C). There were also no significant differences in gastrocnemius or brown adipose tissue between the four groups (Fig. 6D and E). 


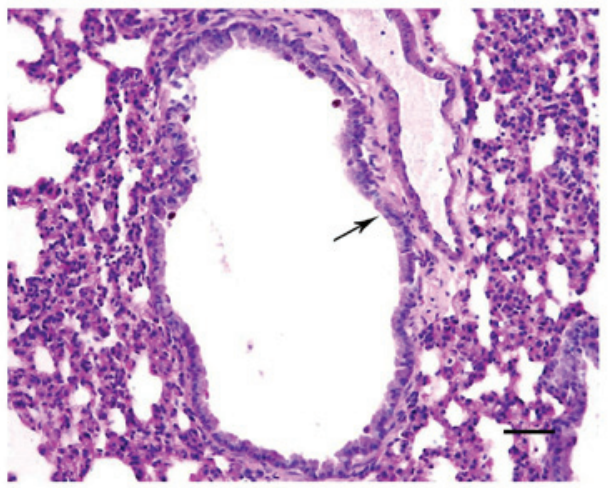

$\mathrm{NC}$

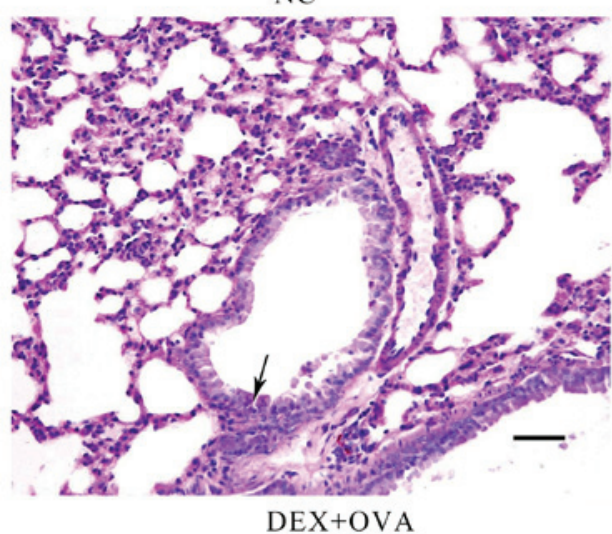

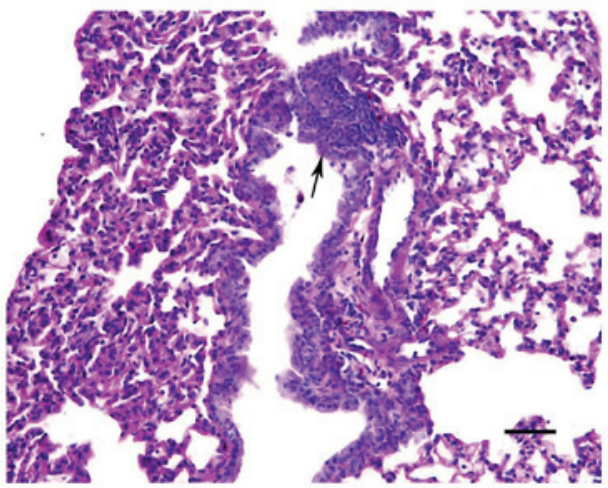

OVA

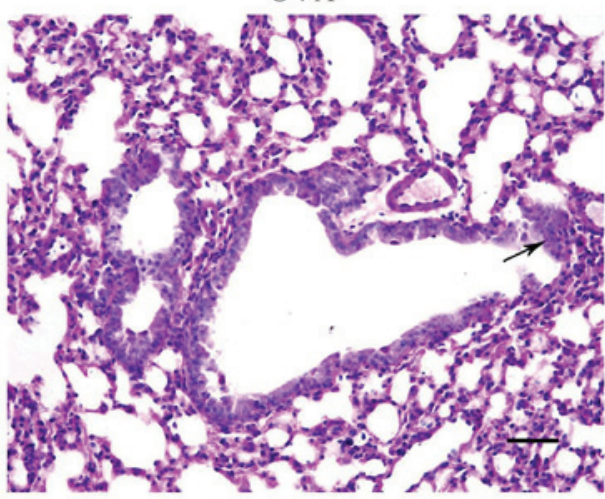

LIM+OVA

Figure 4. Periodic acid-Schiff staining of mucus accumulation. Scale bar=50 $\mu \mathrm{m}$. Arrows indicate areas of mucus accumulation. NC, normal control; OVA, ovalbumin; LIM, limethason; DEX, dexamethasone.

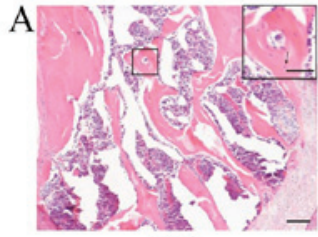

$\mathrm{NC}$

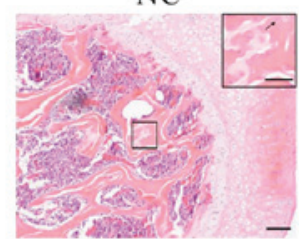

DEX+OVA

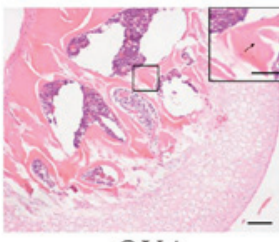
OVA

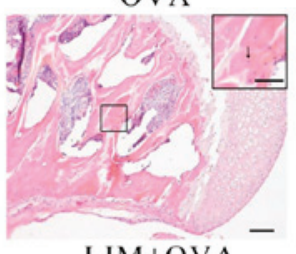

LIM+OVA
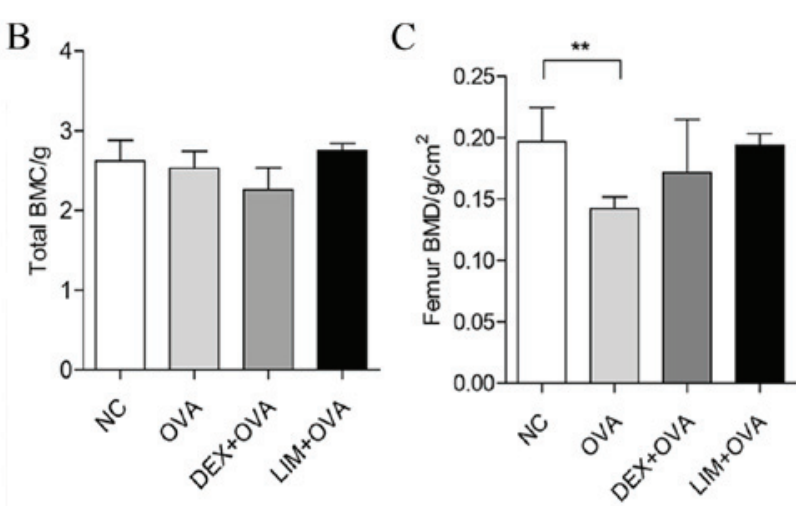

Figure 5. Effect of limethason on bone tissue in an OVA-induced chronic asthma mice model. (A) Hematoxylin and eosin staining for head of femur sections. Scale bar $=100 \mu \mathrm{m}$. Arrows represent osteocytes in bone lacuna. (B) Whole-body BMC. NC group, $\mathrm{n}=8$; OVA group, $\mathrm{n}=7 ; \mathrm{DEX}+\mathrm{OVA}$ group, $\mathrm{n}=12 ; \mathrm{LIM}+\mathrm{OVA}$ group, $n=10$. (C) Femur BMD. NC group, $n=8$; OVA group, $n=12$; DEX + OVA group, $n=12$; LIM + OVA group, $n=11$. Data are presented as the mean \pm standard error of the mean. ${ }^{* *} \mathrm{P}<0.01$. BMC, bone mineral content; BMD, bone mineral density; NC, normal control; OVA, ovalbumin; LIM, limethason; DEX, dexamethasone.

\section{Discussion}

As an effective anti-inflammatory drug, limethason is used for treating multiple disorders, including macrophage activation syndrome, hemophagocytic lymphohistiocytosis and idiopathic pulmonary hemosiderosis $(15,17,18)$. In addition, Hoshi et al (19) demonstrated that this drug has a higher treatment rate of rheumatoid arthritis with lower risk of side effects compared with dexamethasone. To the best of our knowledge, the present study is the first to investigate the effects of limethason on chronic asthma and its side effects. An OVA-induced mouse model of chronic asthma was established using the classical method (20), and dexamethasone was used as a positive control.

AHR is a feature of asthma, which is a chronic disease of the lower respiratory tract (21). In most situations, AHR is associated with airway inflammation, and is the gold standard measurement of bronchial constriction in asthma (22). Penh is an index of air constriction that reflects the level of AHR; the higher the penh value, greater the extent of AHR $(23,24)$. 

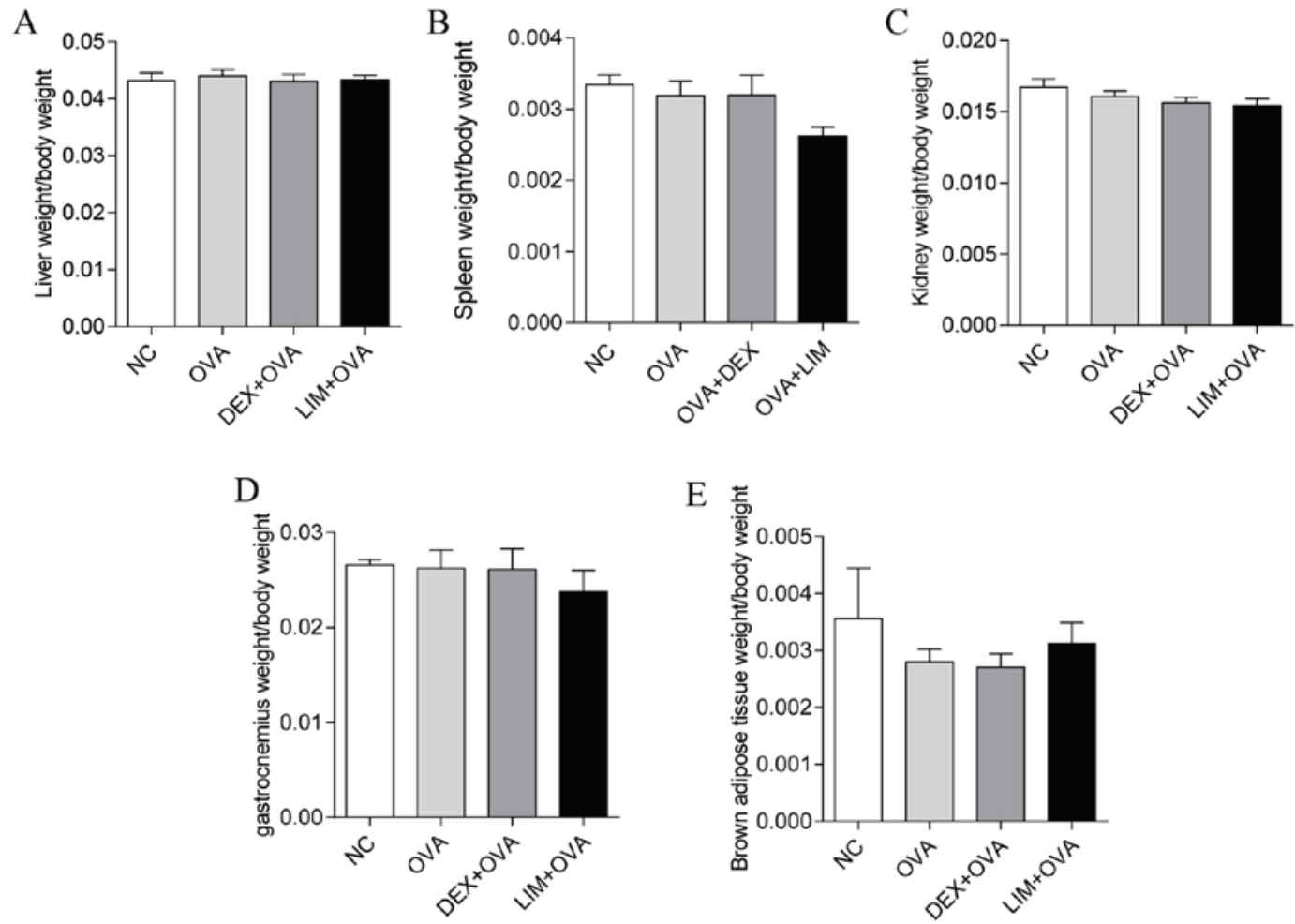

Figure 6. Side effects of limethason on other organs and tissues of mice. The organ/tissue indexes were calculated as followed: Organ or tissue weight/body weight. Data are presented as the mean \pm standard error of the mean. (A and C) Liver and kidney indexes: NC group, $n=7 ;$ OVA group, $n=11 ; \mathrm{DEX}+\mathrm{OVA}$ group, $\mathrm{n}=10$; LIM + OVA group, $\mathrm{n}=11$. (B) Spleen index: NC group, $\mathrm{n}=7$; OVA group, $\mathrm{n}=11$; DEX + OVA group, $\mathrm{n}=10$; LIM + OVA group, $\mathrm{n}=11$. (D) Gastrocnemius index: NC group, $n=7$; OVA group, $n=10 ;$ DEX + OVA, $n=10 ;$ LIM + OVA, $n=11$. (E) Brown adipose tissue index: NC group, $n=7$; OVA group, $n=10$; DEX + OVA, n=10; LIM + OVA, n=11. NC, normal control; OVA, ovalbumin; LIM, limethason; DEX, dexamethasone.

A notable finding in the present study was that limethason effectively inhibits AHR, and was more effective compared with dexamethasone. This result suggested that limethason is a potential bronchodilator for chronic asthma intervention.

To evaluate the suppressive function of limethason on leukocyte infiltration in the lungs of OVA-induced chronic asthma mice, H\&E staining was used in lung tissue sections. The results indicated that limethason notably prevented inflammatory cell infiltration, and was more effective compared with dexamethasone. It is generally accepted that eosinophils are the primary leukocyte to infiltrate in OVA-induced mice (25). Thus, in the present study, the percentage of different leukocyte types was measured in BALF. The data indicated that limethason was more effective at suppressing eosinophils compared with dexamethasone. With regards to the quantity of leukocytes, macrophages and lymphocytes were the prominent types in the BALF of control mice, whereas eosinophils and neutrophils were present at lower levels. These results were consistent with Lei et al (26). Eosinophils are associated with airway remodeling and required for pulmonary mucus accumulation in asthma $(27,28)$. To further investigate the effect of limethason on eosinophils, PAS staining was used to examine mucus secretion in the lungs. The results indicated that limethason markedly inhibited mucus secretion. Mucus secretion increases permeability of the capillary wall, which leads to the serous fluid being exuded. Phlegm is also closely associated with the function of the lung. Therefore, it was proposed that limethason decreases mucus secretion by recovering pulmonary function $(29,30)$.
The key ingredient of limethason is dexamethasone, so the same dose of dexamethasone was used in the DEX + OVA and LIM + OVA groups. It has been established that GCs exhibit harmful effects on bone, muscle and cartilage at histological doses (31). In particular, the excessive use of GCs results in bone loss (32). GCs are the most common cause of secondary osteoporosis and a major reason for non-traumatic osteonecrosis (33). Between 9 and $40 \%$ of patients suffer from osteonecrosis after receiving long-term GC therapy (34). Osteoporosis is a systemic skeletal disorder, which is characterized by low BMD and deteriorating bone micro-architecture (35). In order to survey the side effects of limethason on bone tissue in the present study, H\&E staining of the femur was performed. No notable differences were identified between the groups. Liu et al (36) used dexamethasone up to $2.66 \mathrm{mg} / \mathrm{kg} /$ day for 6 weeks to develop a mouse model of dexamethasone-induced osteonecrosis. Yoon et al (37) used $5 \mathrm{mg} / \mathrm{kg}$ prednisolone to establish a GC-induced osteonecrosis model in rats. However, the dose of dexamethasone in the present study was lower than in these previous studies, which may be the reason that no difference in bone micro-architecture was observed between the groups. However, a novel finding in the present research was that BMD was decreased in the OVA group. It has been verified that asthma has a association with BMD, and asthma is a well-known risk factor to osteoporosis $(38,39)$.

It is well known that organ weight is a sensitive indicator of drug toxicity. Organ weight and organ index are key characteristics that indicate the health of organisms. To detect the effect of limethason on organs and tissues, organ and tissue indexes 
were measured in the present study. However, no significant differences were observed between the groups. These results indicated that limethason did not damage the liver, spleen, kidney, gastrocnemius or brown adipose tissue. Notably, dexamethasone did not seem to cause any damage either. This is a limitation in this study. The present results for gastrocnemius and brown adipose tissue were inconsistent with the findings of previous studies $(40,41)$. This may be because the duration of the experiment was not long enough. Although it has been reported that dexamethasone induces skeletal muscle atrophy (42), overuse of GC is also associated with human obesity (43). The present results for gastrocnemius and brown adipose tissue were inconsistent with the findings of previous studies. This may be because the duration of the experiment was not long enough to observe marked differences between groups.

In conclusion, the present study confirmed that limethason suppresses inflammation in an OVA-induced chronic asthma murine model, and briefly evaluated adverse reactions to limethason. The present results indicated that limethason effectively inhibits AHR, leukocyte (particularly eosinophil) infiltration and mucus hypersecretion, but does not cause side effects on the head of femur, liver, spleen, kidney, gastrocnemius or brown adipose tissue. These results indicate that limethason may be more effective for treating chronic asthma compared with dexamethasone, with no obvious side effects on tissues or organs during treatment. The present study provides a novel approach for treating chronic asthma, and limethason could potentially be used instead of dexamethasone for treating chronic asthma. The underlying molecular mechanism of limethason could be investigated in future studies.

\section{Acknowledgements}

This study was supported by the Fundamental Research Funds for the Central Universities (grant no. lzujbky-2015-188) and the National Natural Science Foundation of China (grant no. 81601913).

\section{References}

1. Djukanović R, Roche WR, Wilson JW, Beasley CR Twentyman OP, Howarth RH and Holgate ST: Mucosal inflammation in asthma. Am Rev Respir Dis 142: 434-457, 1990.

2. Lee M, Kim S, Kwon OK, Oh SR, Lee HK and Ahn K Anti-inflammatory and anti-asthmatic effects of resveratrol, a polyphenolic stilbene, in a mouse model of allergic asthma. Int Immunopharmacol 9: 418-424, 2009.

3. Barnes PJ: Glucocorticosteroids: Current and future directions. Br J Pharmacol 163: 29-43, 2011.

4. Barnes PJ: Mechanisms and resistance in glucocorticoid control of inflammation. J Steroid Biochem Mol Biol 120: 76-85, 2010.

5. Parikh K, Hall M, Mittal V, Montalbano A, Gold J, Mahant S, Wilson KM and Shah SS: Comparative effectiveness of dexamethasone versus prednisone in children hospitalized with asthma. J Pediatr 167: 639-44 e14, 2015.

6. van Vollenhoven RF: Treatment of rheumatoid arthritis: State of the art 2009. Nat Rev Rheumatol 5: 531-541, 2009.

7. Peine KJ, Guerau-de-Arellano M, Lee P, Kanthamneni N, Severin M, Probst GD, Peng H, Yang Y, Vangundy Z, Papenfuss TL, et al: Treatment of experimental autoimmune encephalomyelitis by codelivery of disease associated Peptide and dexamethasone in acetalated dextran microparticles. Mol Pharm 11: 828-835, 2014
8. Jiang X, Zhao M, Wang Y, Zhu H, Zhao S, Wu J, Song Y and Peng S: RGD (F/S/V)-Dex: Towards the development of novel, effective and safe glucocorticoids. Drug Des Devel Ther 10: 1059-1076, 2016

9. Ren H, Liang D, Jiang X, Tang J, Cui J, Wei Q, Zhang S, Yao Z, Shen $G$ and Lin S: Variance of spinal osteoporosis induced by dexamethasone and methylprednisolone and its associated mechanism. Steroids 102: 65-75, 2015 .

10. Daull P, Paterson CA, Kuppermann BD and Garrigue JS: A preliminary evaluation of dexamethasone palmitate emulsion: A novel intravitreal sustained delivery of corticosteroid for treatment of macular edema. J Ocul Pharmacol Ther 29: 258-269, 2013.

11. Anderson R, Franch A, Castell M, Perez-Cano FJ, Bräuer R, Pohlers D, Gajda M, Siskos AP, Katsila T, Tamvakopoulos C, et al: Liposomal encapsulation enhances and prolongs the anti-inflammatory effects of water-soluble dexamethasone phosphate in experimental adjuvant arthritis. Arthritis Res Ther 12: R147, 2010.

12. Nishiwaki S, Nakayama T, Murata M, Nishida T, Terakura S, Saito S, Kato T, Mizuno H, Imahashi N, Seto A, et al: Dexamethasone palmitate ameliorates macrophages-rich graft-versus-host disease by inhibiting macrophage functions. PLoS One 9: e96252, 2014.

13. Chono S, Tauchi Y and Morimoto K: Aortic drug delivery of dexamethasone palmitate incorporated into lipid microspheres and its antiatherosclerotic effect in atherogenic mice. J Drug Target 13: 407-414, 2005.

14. Yang Y, Li H, Gao K, Liu M, Sun Y, Yan T, Fawcett JP, Cui Y and Gu J: Simultaneous quantitation of dexamethasone palmitate and dexamethasone in human plasma by liquid chromatography/tandem mass spectrometry. J Chromatogr B Analyt Technol Biomed Life Sci 862: 119-124, 2008.

15. Doi T, Ohga S, Ishimura M, Takada H, Ishii K, Ihara K, Nagai H and Hara T: Long-term liposteroid therapy for idiopathic pulmonary hemosiderosis. Eur J Pediatr 172: 1475-1481, 2013.

16. Janet C. Garber: Guide for The Care Laboratory Animals. 8th edition. The National Academics press, Washington, DC, pp1-175.c14, 2011.

17. Otsubo K, Fukumura A, Hirayama M, Morimoto T, Kato M and Mochizuki H: Hemophagocytic lymphohistiocytosis caused by systemic herpes simplex virus type 1 infection: Successful treatment with dexamethasone palmitate. Pediatr Int 58: 390-393, 2016.

18. Nakagishi Y, Shimizu M, Kasai K, Miyoshi M and Yachie A: Successful therapy of macrophage activation syndrome with dexamethasone palmitate. Mod Rheumatol 26: 617-620, 2016.

19. Hoshi K, Mizushima Y, Shiokawa Y, Kageyama T, Honma M, Kashiwazaki S, Shichikawa K, Tsunematsu T and Kaneko K: Double-blind study with liposteroid in rheumatoid arthritis. Exp Clin Res 11: 621-626, 1985.

20. Jain VV, Kitagaki K, Businga T, Hussain I, George C, O'shaughnessy P and Kline JN: CpG-oligodeoxynucleotides inhibit airway remodeling in a murine model of chronic asthma. J Allergy Clin Immunol 110: 867-872, 2002.

21. Freishtat RJ, Nagaraju K, Jusko W and Hoffman EP: Glucocorticoid efficacy in asthma: Is improved tissue remodeling upstream of anti-inflammation. J Investig Med 58: 19-22, 2010.

22. Liang Z, Xu Y, Wen X, Nie H, Hu T, Yang X, Chu X, Yang J, Deng $X$ and He J: Rosmarinic acid attenuates airway inflammation and hyperresponsiveness in a murine model of asthma. Molecules 21: pii: E769, 2016.

23. Deng Y, Chen W, Zang N, Li S, Luo Y, Ni K, Wang L, Xie X, Liu W, Yang X, et al: The antiasthma effect of neonatal BCG vaccination does not depend on the Th17/Th1 but IL-17/IFN- $\gamma$ balance in a BALB/c mouse asthma model. J Clin Immunol 31: 419-429, 2011.

24. Huang CQ, Li W, Wu B, Chen WM, Chen LH, Mo GW, Zhang QF, Gong L, Li J, Zhang HC, et al: Pheretima aspergillum decoction suppresses inflammation and relieves asthma in a mouse model of bronchial asthma by NF- $\mathrm{BB}$ inhibition. J Ethnopharmacol 189: 22-30, 2016.

25. Kim SG, Lee E, Park NY, Park HH, Jeong KT, Kim KJ, Lee YJ, Jin $\mathrm{M}$ and Lee E: Britanin attenuates ovalbumin-induced airway inflammation in a murine asthma model. Arch Pharm Res 39: 1006-1012, 2016.

26. Lei W, Zeng DX, Zhu CH, Liu GQ, Zhang XQ, Wang CG, Wang $\mathrm{Q}$ and Huang JA: The upregulated expression of OX40/OX40L and their promotion of T cells proliferation in the murine model of asthma. J Thorac Dis 6: 979-987, 2014. 
27. Lee JJ, Dimina D, Macias MP, Ochkur SI, McGarry MP, O'Neill KR, Protheroe C, Pero R, Nguyen T, Cormier SA, et al: Defining a link with asthma in mice congenitally deficient in eosinophils. Science 305: 1773-1776, 2004.

28. Humbles AA, Lloyd CM, McMillan SJ, Friend DS, Xanthou G, McKenna EE, Ghiran S, Gerard NP, Yu C, Orkin SH and Gerard C: A critical role for eosinophils in allergic airways remodeling. Science 305: 1776-1779, 2004.

29. Zhao YT, Zhang XG, Bai L, Li LQ and Yu JE: Effects of Chinese herbal medicine Pingchuan Formula on airway inflammation, interferon- $\gamma$ and interleukin- 4 in mice with asthma. Zhong Xi Yi Jie He Xue Bao 10: 807-813, 2012 (In Chinese).

30. Liu F, Yu J, Bai L, Xue Z and Zhang X: Pingchuan formula improves asthma via restoration of the Th17/Treg balance in a mouse model. BMC Complement Altern Med 15: 234, 2015.

31. Hardy R and Cooper MS: Glucocorticoid-induced osteoporosis-a disorder of mesenchymal stromal cells? Front Endocrinol (Lausanne) 2: 24, 2011.

32. Zhu FB, Wang JY, Zhang YL, Quan RF, Yue ZS, Zeng LR, Zheng WJ, Hou Q, Yan SG and Hu YG: Curculigoside regulates proliferation, differentiation, and pro-inflammatory cytokines levels in dexamethasone-induced rat calvarial osteoblasts. Int J Clin Exp Med 8: 12337, 2015.

33. Weinstein RS: Glucocorticoid-induced osteoporosis and osteonecrosis. Endocrinol Metab Clin North Am 41: 595-611, 2012.

34. Weinstein RS: Glucocorticoid-induced osteonecrosis. Endocrine 41: 183-190, 2012.

35. Bilezikian JP: Combination anabolic and antiresorptive therapy for osteoporosis: Opening the anabolic window. Curr Osteoporos Rep 6: 24-30, 2008.

36. Liu C, Janke LJ, Kawedia JD, Ramsey LB, Cai X, Mattano LA Jr, Boyd KL, Funk AJ and Relling MV: Asparaginase potentiates glucocorticoid-induced osteonecrosis in a mouse model. PLoS One 11: e0151433, 2016.
37. Yoon HY, Cho YS, Jin Q, Kim HG, Woo ER and Chung YS: Effects of ethyl acetate extract of poncirus trifoliata fruit for glucocorticoid-induced osteoporosis. Biomol Ther (Seoul) 20: 89-95, 2012.

38. Lee DW and Choi EY: A comparative study of bone mineral density among patients with obstructive lung diseases in Korea. Int J Tuberc Lung Dis 19: 1246-1251, 2015.

39. Jung JW, Kang HR, Kim JY, Lee SH, Kim SS and Cho SH: Are asthmatic patients prone to bone loss? Ann Allergy Asthma Immunol 112: 426-431, 2014.

40. Kim JW, Ku SK, Han MH, Kim KY, Kim SG, Kim GY, Hwang HJ, Kim BW, Kim CM and Choi YH: The administration of Fructus Schisandrae attenuates dexamethasone-induced muscle atrophy in mice. Int J Mol Med 36: 29-42, 2015.

41. Lv Y, Yu J, Sheng Y, Huang M, Kong X, Di W, Liu J, Zhou H, Liang $\mathrm{H}$ and Ding G: Glucocorticoids suppressing the browning of adipose tissue via miR-19b in male mice. Endocrinology: Oct 24, 2017 (Epub ahead of print).

42. Massaccesi L, Goi G, Tringali C, Barassi A, Venerando B and Papini N: Dexamethasone-induced skeletal muscle atrophy increases O-GlcNAcylation in $\mathrm{C} 2 \mathrm{C} 12$ cells. J Cell Biochem 117: 1833-1842, 2016.

43. Mammi CM, Marzolla V, Armani A, Feraco A, Antelmi A, Maslak E, Chlopicki S, Cinti F, Hunt H, Fabbri A and Caprio M: A novel combined glucocorticoid-mineralocorticoid receptor selective modulator markedly prevents weight gain and fat mass expansion in mice fed a high-fat diet. Int J Obes (Lond) 40: 964-972, 2016

(i) () This work is licensed under a Creative Commons c. At No No Atribution-NonCommercial-NoDerivatives 4.0 International (CC BY-NC-ND 4.0) License. 